Revista de Educação e Pesquisa em Contabilidade Journal of Education and Research in Accounting Revista de Educación e Investigatión en Contabilidad
REPeC, Brasília, v. 6, n. 4, art. 6, p. 434-447, out./dez. 2012 Disponível online em www.repec.org.br ISSN 1981-8610

\title{
Normas Brasileiras e Internacionais de Contabilidade Aplicadas ao Setor Público e o Desafio da Convergência: uma Análise Comparativa - IPSAS e NBCTSP
}

\section{Adriana Rodrigues Fragoso}

Mestre em Ciências Contábeis pelo Programa Multiinstitucional e Inter-regional de pós-graduação em Ciências Contábeis (UnB, UFPB, UFPE, UFRN)

Av. Mario Alvares Pereira de Lira, 905, Bl02, Ap.106, Bairro Iputinga, Recife, PE.

E-mail: adrianarodriguesf@yahoo.com.br

\section{João Marcelo Alves Macêdo}

Mestre em Ciências Contábeis pela UFPE

Professor Assistente I da Universidade Federal da Paraiba (UFPB)

Rua Valdemar Felix dos Santos, 140 - Managabeira I - João Pessoa, PB

E-mail:jmmarcelopb@gmail.com

\section{Jorge Expedito de Gusmão Lopes}

Doutor em Educação, Liderança e Chefia

Diretor Gerente da L \& P Educacional

Rua Padre Carapuceiro 273 apto. 51, Boa Viagem,PE.

Emaisl: professorjorgelopes@gmail.com

\section{José Francisco Ribeiro Filho (in memorian)}

Doutor em Controladoria e Contabilidade

Universidade Federal de Pernambuco (UFPE)

\section{Marcleide Maria Macêdo Pederneiras}

Doutoranda em Administração/PROPAD/UFPE

Professora Assistente da Universidade Federal da Paraíba (UFPB) - Campus IV

Rua Telegrafista Cícero Caldas, 206 Bairro dos Estados - João Pessoa, PB

E-mail:marcleide@gmail.com

\section{Resumo}

O presente estudo tem por objetivo analisar o estágio atual de convergência conceitual entre as normas brasileiras de contabilidade aplicadas ao setor público (NBCTSP) e as International Public Sector Accounting Standard (IPSAS). A complexidade e diversidade de transações entre entidades do setor público ou privado, gerada pela internacionalização de mercados, demandam uma avaliação contínua e dinâmica dos eventos que promovem a modificação

Editado em Português, Inglês e Espanhol. Versão original em Português.

Recebido em 12/01/2011. Pedido de Revisão em 30/06/2011. Resubmetido em 23/11/2011. Aceito em 12/12/2011 por Valcemiro Nossa (Editor). Publicado em 30/11/2012. Organização responsável pelo periódico: CFC/FBC/ABRACICON.

Copyright (C) 2012 REPEC. Todos os direitos, até mesmo de tradução, são reservados. É permitido citar parte de artigos sem autorização prévia, desde que seja identificada a fonte. 


\section{repec}

quantitativa ou qualitativa de um patrimônio. Para esse processo de avaliação, a observação dos princípios e normas de contabilidade é importante para garantir, entre outras características da informação, a compreensibilidade e comparabilidade, reduzindo custos aos investidores e usuários, em geral, considerando as barreiras encontradas na diversidade de idiomas, culturas, políticas fiscais e econômicas. Para a análise de convergência, foi efetuado um estudo comparativo do conteúdo das normas, a partir de uma análise descritiva, com o intuito de verificar a aderência existente entre as normas brasileiras e internacionais aplicadas ao setor público. Os resultados encontrados destacam que ainda há diversos aspectos a serem discutidos para uma efetiva convergência às normas internacionais; esta convergência atual é parcial. No entanto, verifica-se que as NBCTSPs apresentam uma exposição conceitual de qualidade enquanto as IPSAS apresentam um conteúdo mais focado em procedimentos operacionais.

Palavras-Chave: Convergência; Internacionalização; Setor Público.

\section{INTRODUÇÃO}

A definição exitosa de um processo voltado à utilização de um mesmo conjunto de regras, procedimentos e conceitos contábeis por todas as organizações em um mesmo país e, na sequência, por todos os países, decorre do fenômeno mais amplo e complexo, que conjuga o desenvolvimento e o acesso cada vez mais facilitado de tecnologias de informação e comunicação (TICs); a ampliação do comércio internacional; e o impacto das sucessivas crises de confiança derivadas de falhas de integridade de gestores, conselhos e auditores de grandes organizações públicas e privadas.

Por outro lado, a Contabilidade, enquanto ciência social, busca desenvolver uma metodologia para subsidiar a aplicação de seus artefatos técnicos, também segundo uma perspectiva de "linguagem universal de negócios". O pressuposto, portanto, é que este "idioma" - a Contabilidade - deveria ser capaz de gerar, em decorrência de seu padrão de mensuração e informação de eventos econômicos, um ambiente de comunicação com alcance, ao mesmo tempo, local e global.

No entanto, variáveis culturais vigentes entre os países, entre países integrantes do mesmo bloco econômico e, mesmo, entre regiões de um mesmo país suscitam desafios, por assim dizer "linguísticos", para a Contabilidade, que tem enfraquecido ou pelo menos adiado, o intento da universalização tanto conceitual quanto prática.

Porém, o esforço por uma universalização dos padrões e conceitos contábeis continua em ritmo cada vez mais intenso, agora sob um arcabouço mais sistemático, que perpassa desde um processo de adoção das normas, passando pela harmonização e agora apontando para a convergência com base nos padrões internacionais.

O Brasil experimenta e vivencia este processo. No setor privado, a edição das Leis n. ${ }^{\text {ss }} 11.638 / 07$ e 11.941/09, que alteraram dispositivos da anterior Lei n. ${ }^{\circ}$ 6.404/76 das Sociedades por Ações, para incorporar procedimentos e regras contábeis contidas nas normas internacionais de contabilidade IAS/ IFRS (International Accounting Standard/International Financial Reporting Standard), emanadas do IASB (International Accounting Standard Board). E, no caso do setor público, o trabalho em desenvolvimento pelo Grupo Assessor constituído pelo Conselho Federal de Contabilidade (CFC), para a elaboração das Normas Brasileiras de Contabilidade Técnicas Aplicadas ao Setor Público (NBCTSP), culminando com a publicação da Resolução CFC n. ${ }^{\circ}$ 1.111/07, que aproxima a aplicação dos Princípios Fundamentais de Contabilidade para o setor público; e as Resoluções n. ${ }^{\text {os }} 1.128 / 08$ até 1.137/08, no total de dez normas técnicas até o momento. E na extensão a formação, também pelo CFC, do Grupo de Trabalho da Convergência no Setor Público (GTCP), para cumprimento da agenda da convergência, até 2012, em direção às International Public Sector Accounting Standard (IPSAS), publicadas pela International Federation on Accountants (IFAC).

Este artigo, portanto, analisa o desafio da convergência contábil no setor público brasileiro, bem como questões de interpretação, linguagem e terminologia, entre as normas internacionais de contabilidade voltadas ao setor público, produzidas pela IFAC e o contexto conceitual vigente nas normas brasileiras de contabilidade aplicadas ao setor público produzidas pelo CFC. 
Observa-se este cenário sob o pressuposto de que a Contabilidade é uma ciência social e, portanto, elabora e aperfeiçoa seus artefatos técnicos e bem assim seus conceitos, normas e procedimentos, como fruto de um processo de construção social. Dessa forma, os fenômenos contábeis mensurados e reportados traduzem os embates advindos de pesquisas que estão imersas no cadinho da luta pela afirmação acadêmica e profissional de grupos, bem como de crenças, valores e opções políticas vigentes no contexto econômico, que definem a forma como deve ocorrer o arbitramento do conflito distributivo advindo da criação, movimentação e distribuição da riqueza.

\subsection{Definição do problema e objetivos}

Os esforços para dotar a Contabilidade de um padrão de comunicação inequívoco, de forma que tanto o sistema de mensuração dos fenômenos contábeis quanto a denominação ou título atribuído para cada um possam ser prontamente compreensíveis em qualquer contexto, são tão antigos e continuam sendo tão atuais e necessários. Anthony (2003, p. 21), no seu livro "Rethinking the Rules of Financial Accounting - Examining the Rules for Proper Reporting”, comenta:

Em 1998 eu fiz um estudo em torno dos conceitos e padrões do FASB, onde ficou evidenciado que frequentemente dois nomes distintos são utilizados para designar um mesmo item. Por exemplo, "operating income" foi utilizado 356 vezes e "operating profit" foi usado 146 vezes. Por outro lado não existiam definições prévias para cada termo, de forma que a compreensão deles pode ser deslocada do contexto ficando ao sabor de várias interpretações.

O desenvolvimento de uma linguagem única e comum a ser utilizada como uma estrutura contábil universal aponta para a definição de uma taxonomia, estruturada em um sistema hierárquico de termos, no sentido dado, por exemplo, à organização adotada nas ciências biológicas, de gênero, espécies, filo, classes, ordens, etc. No caso da Contabilidade, busca-se um padrão de comunicação que seja a base da linguagem universal que se pretende. Anthony (2003, p. 23) exemplifica com os esforços em torno de um corpo conceitual para os negócios em escala global, a partir da adoção do padrão XBRL (eXtensible Business Reporting Language), que deveria se constituir em padrão de linguagem computacional, com impactos nos sistemas corporativos, trocas de arquivos e os reflexos na confecção de relatórios contábeis.

Ainda na visão de Anthony (2003, p. 22), este panorama deveria trilhar a uniformização, inclusive, para termos contábeis entre os ambientes de atuação dos setores privado, não governamental e também governamental:

Pronunciamentos recentes de regras contábeis para os setores não governamentais (sem fins lucrativos) e governamentais usam termos diferentes daqueles utilizados no ambiente de negócios com fins lucrativos. Isto é desnecessário e confuso. A terminologia própria no ambiente comercial deve ser utilizada nos ambientes de governo e no setor não voltado ao lucro, quando denotarem fenômenos semelhantes.

Por outro lado, esse processo não ocorre de forma imediata. E ao mesmo tempo em que se apresenta como provavelmente simples de ser percebido e até desejado, na perspectiva de um possível avanço para a Contabilidade no fortalecimento da comunicação com os stakeholders, essencialmente é complexo, multifacetado e polissêmico.

Em novembro de 2006, por exemplo, o IASB emitiu um documento (discusion paper), intitulado Fair Value Measurements (mensuração a valor justo), para ampliar a discussão e convergir o entendimento sobre fair value contido nas IFRS e aquele exposto no Statement of Financial Accounting Standard 157 (SFAS 157), emitido pelo Financial Accounting Standard Board (FASB), que é uma entidade Estadunidense responsável por gerar o padrão US GAAP. Ou seja, surge uma necessidade de 


\section{repec}

convergência conceitual para explicar um mesmo título, o fair value, mesmo quando tratados na mesma língua inglesa pelo órgão normatizador internacional (IASB) e aquele dos Estados Unidos (FASB). Para o IASB, fair value significa um valor de consenso em uma transação sem favorecimento. Para o FASB fair value está associado ao conceito de valor de saída ou de mercado.

O Professor Zeff (2007) discute que os obstáculos à comparabilidade das demonstrações contábeis entre empresas de países diferentes e também à convergência de normas contábeis entre os países são, respectivamente, de ordem cultural e envolvem problemas de interpretação, de linguagem e de terminologia.

No Brasil o CFC editou, em 2008, as normas brasileiras técnicas de contabilidade aplicadas ao setor público (NBCTSPs), fato inédito desde que o Sistema CFC/CRCs foi organizado há mais de 60 anos. Ao mesmo tempo, estabeleceu um cronograma para a convergência das NBCTSPs com as IPSAS, de forma que o país possa se inscrever no rol daquelas nações que caminham para a incorporação de padrões uniformes de contabilidade para o setor público.

Com a visão de que um processo de convergência implica considerar variáveis culturais, para além de questões puramente técnicas em contabilidade, este estudo se orienta pela seguinte questão: Qual o estágio atual de convergência conceitual entre as normas brasileiras de contabilidade aplicadas ao setor público (NBCTSPS) e as IPSAS?

Para direcionar as reflexões em torno da questão proposta, pensa-se atingir o seguinte objetivo geral e os respectivos objetivos específicos: verificar o estágio de convergência conceitual entre as NBCTSPs e as IPSAS; analisar a aderência dos conceitos contidos nas NBCTSPs segundo aqueles contidos nas IPSAS; inferir sobre o estágio atual de convergência das NBCTSPs às normas internacionais voltadas ao setor público.

\section{PLATAFORMA TEÓRICA}

Diante da complexidade e diversidade de transações entre entidades, seja do setor público ou privado, a contínua e dinâmica avaliação de eventos que promovem a modificação quantitativa ou qualitativa de um patrimônio é um desafio. Para isso, é necessário que os procedimentos sejam orientados por princípios e normas que consistem em "...expressões de direito positivo, que a partir dos princípios estabelecem ordenamentos sobre o 'como fazer', isto é, técnicas, procedimentos, métodos, critérios, etc., tanto nos aspectos substantivos, quanto nos formais..." (CFC, 2008, p. 19).

Com a internacionalização de mercados e a diversidade de fatos, a necessidade de harmonização de normas, de avaliação, de convergência e revisão de procedimentos contábeis torna-se imprescindível e desafiadora.

Um aspecto relevante é entender a enorme dificuldade vivenciada pelos integrantes das entidades contábeis normatizadoras. Esses vivenciam grandes dualidades, como a necessidade de definir se devem aumentar o número de normas acompanhando todas as novas operações realizadas pelas empresas ou exercer a regulação baseada em princípios. Ao mesmo tempo, devem definir como equilibrar a postura rígida necessária, sem que haja restrição total sobre a capacidade do profissional da contabilidade em retratar a realidade de acordo com as características da empresa e da transação econômica realizada. E, também, como garantir a aplicação da essência econômica sobre a forma jurídica. (SZUSTER et al., 2005, p.22-23)

O desafio é estabelecer normas convergentes para garantir a qualidade da informação produzida pela Contabilidade, manter os padrões de compreensibilidade e comparabilidade, reduzindo os custos associados a esse processo pelos investidores e usuários em geral, considerando as barreiras encontradas na diversidade de idiomas, culturas, política fiscal e econômica, por exemplo. 
La interdependencia creciente en los mercados fi nancieros mundiales exige una mejora de La comparabilidad de la información fi nanciera de todas las empresas que actúan en un mismo mercado globalizado, a través de un acercamiento de las legislaciones contables. (MANZANO, CONESA, 2005, p.104)

Por isso, o processo de convergência de normas contábeis às normas internacionais é um esforço que envolve diversos países. Na Argentina, por exemplo, Manzano e Conesa (2005, p.107) destacam que o movimento foi dividido em duas etapas:

En la primera etapa de trabajo se procedió a definir el modelo contable argentino armonizador, estableciendo los cambios necesarios para evitar diferencias con las Normas Internacionales, e incorporando temas no tratados en las normas argentinas y sí en las internacionales (leasing, combinaciones de negocios, instrumentos financieros, utilidad por acción, información por segmentos, entre otros). Durante la segunda etapa se comenzaron a realizar modificaciones de las Resoluciones Técnicas vigentes, proponiéndose a la vez otras nuevas.

As autoras comentam ainda sobre o processo de convergência no Brasil, no Chile, no México. No entanto, Pohlmann (1995,p 3) ressalta que

existe um consenso de que para compreender qualquer sistema contábil em particular, deve-se considerar os sistemas culturais, sociais, econômicos, legais e religiosos de um país. No caso de países desenvolvidos, esses fatores podem ser suficientes para possibilitar classificações razoavelmente consistentes no tempo; mas infelizmente em países em desenvolvimento, mudanças no ambiente podem ser frequentes e dramáticas, reduzindo a significância de qualquer tentativa de categorização.

Os fatores discutidos por Pohlmann (1995) são relevantes, mas quando se avalia a crise internacional, na qual os EUA ainda se encontram em processo de recuperação, a partir de medidas adotadas pelo governo, com destaque para o bom desempenho do Brasil (reconhecido mundialmente), torna-se falho o argumento de que países desenvolvidos poderão ter bases sólidas para definição de sistemas consistentes. Percebe-se que o cenário atual é mais instável do que parece, o que resulta em um processo de convergência ainda mais complexo do que em anos anteriores.

Percebe-se ainda que o processo de convergência das normas é tratado com ênfase em investimentos, transações internacionais, mercados de capitais, com foco em empresas de capital aberto. Há uma escassez de referências bibliográficas que tratam a convergência das normas de contabilidade no setor público.

\section{METODOLOGIA}

Este estudo se inscreve na visão metodológica proposta por Popper (1975), de que a essência do método científico é estabelecer uma abordagem sistemática que sirva de direcionador para explicar um conjunto de fenômenos categorizados como semelhantes.

Utiliza-se o método dedutivo, onde o conjunto das normas identificadas como IPSAS e NBCTSPs, todas disponibilizadas nos respectivos sítios de seus órgãos emissores, oferecem o espaço de análise que será percorrido para a identificação das premissas a serem consideradas, ou seja, o explicans proposto por Popper (1982). A partir da identificação das premissas, que são o conjunto de conceitos vigentes nas normas, deduz-se o explicandum, que é o conjunto de conceitos que se pretende explicar por estarem presentes nos três ambientes normativos. 
O comparativo foi elaborado, partindo-se da verificação da convergência de cada tópico conceitual constante nas NBCTSPs (considerando a numeração existente no corpo delas) com as IPSAS. Utilizou-se a estatística descritiva para quantificar quantos tópicos e subtópicos eram contemplados, ou não, pelas normas internacionais aplicadas ao setor público. Dessa forma, foi possível encontrar o percentual de convergência, apresentado na Tabela 2. É importante salientar que foram considerados apenas os tópicos conceituais válidos das NBCTSPs, excluindo-se os tópicos denominados "disposições gerais", que tratam apenas da apresentação de cada norma.

Após essa avaliação de convergência, o estudo comparativo evidencia os tópicos que são convergentes entre as normas brasileiras e internacionais, bem como apresenta os fatos não contemplados ou divergentes.

\section{ANÁLISE COMPARATIVA - IPSAS E NBCTSP}

A análise de convergência utilizou uma base comparativa, que apresenta as IPSAS correspondentes às normas brasileiras NBCTSPs, com a inclusão, também das normas IAS/IFRS, em razão da semelhança conceitual existente entre as normas emitidas pelo IASB para o setor privado e aquelas emitidas pela IFAC, no caso as IPSAS, voltadas ao setor público. Percebe-se, de imediato, que o conteúdo conceitual vigente nas IAS/IFRS são bastante aproximados daquele vigente nas IPSAS, sugerindo uma aproximação conceitual significativa para os ambientes contábeis prevalecentes no setor privado (IAS/IFRS) e no setor público (IPSAS).

Essa situação, antes da edição das NBCTSPs pelo CFC, colocava os ambientes contábeis do setor privado e do setor público no Brasil, em campos bastante distintos, a ponto de se mencionar a existência de "duas contabilidades" totalmente diferentes. Com a edição das NBCTSPs ocorre uma aproximação conceitual, entre a contabilidade do setor privado e a contabilidade do setor público no Brasil, até então inexistentes na prática contábil. No Quadro 1, são apresentadas as correspondências entre as normas IPSAS/IFAC x IAS-IFRS/IASB x NBCTSPs/CFC.

\begin{tabular}{|c|c|c|}
\hline IPSAS/IFAC & IAS-IFRS/IASB & NBCTSPs/CFC \\
\hline \multirow{2}{*}{$\begin{array}{l}\text { IPSAS } 1 \text { - Presentation of } \\
\text { Financial Statements. }\end{array}$} & \multirow{2}{*}{$\begin{array}{l}\text { IAS } 1 \text { - Apresentação das demonstrações } \\
\text { financeiras (Presentation of Financial } \\
\text { Statements) }\end{array}$} & $\begin{array}{l}\text { NBC T } 16.1 \text { - Conceituação, Objeto e } \\
\text { Campo de Aplicação; }\end{array}$ \\
\hline & & NBC T 16.6 - Demonstrações Contábeis \\
\hline IPSAS 2 - Cash Flow Statements & $\begin{array}{l}\text { IAS } 7 \text { - Demonstração dos fluxos de } \\
\text { caixa (Cash Flow Statements) }\end{array}$ & NBC T 16.6 - Demonstrações Contábeis \\
\hline $\begin{array}{l}\text { IPSAS } 3 \text { - Net Surplus or Deficit } \\
\text { for the Period - Fundamental } \\
\text { Errors and Changing in } \\
\text { Accounting Policies }\end{array}$ & $\begin{array}{l}\text { IAS } 8 \text { - Políticas contábeis, alterações de } \\
\text { estimativas e Erros (Accounting Policies, } \\
\text { Changes in Accounting Estimates and } \\
\text { Errors) }\end{array}$ & $\begin{array}{l}\text { NBC T } 16.4 \text { - Transações no Setor } \\
\text { Público (PFCs - Accrual Basis) }\end{array}$ \\
\hline $\begin{array}{l}\text { IPSAS } 4 \text { - The Effects of } \\
\text { changes in Foreign Exchange } \\
\text { Rates }\end{array}$ & $\begin{array}{l}\text { IAS } 21 \text { - Efeitos das alterações nas taxas } \\
\text { de câmbio (The Effects of Changes in } \\
\text { Foreign Exchange Rates) }\end{array}$ & N/A \\
\hline IPSAS 5 - Borrowing Costs & $\begin{array}{l}\text { IAS } 23 \text { - Custos de empréstimos } \\
\text { (Borrowing Costs) }\end{array}$ & $\mathrm{N} / \mathrm{A}$ \\
\hline $\begin{array}{l}\text { IPSAS } 6 \text { - Consolidated } \\
\text { Financial Statements - } \\
\text { Accounting for Controlled } \\
\text { Entities }\end{array}$ & $\begin{array}{l}\text { IAS } 27 \text { - Demonstrações financeiras } \\
\text { consolidadas e contabilidade para } \\
\text { investimentos em subsidiárias } \\
\text { (Consolidated and Separate Financial } \\
\text { Statements) }\end{array}$ & $\begin{array}{l}\text { NBC T } 16.7 \text { - Consolidação das } \\
\text { Demonstrações Contábeis }\end{array}$ \\
\hline
\end{tabular}




\begin{tabular}{|c|c|c|}
\hline IPSAS/IFAC & IAS-IFRS/IASB & NBCTSPs/CFC \\
\hline \multirow{2}{*}{$\begin{array}{l}\text { IPSAS } 7 \text { - Accounting for } \\
\text { Investments in Associates }\end{array}$} & \multirow{2}{*}{$\begin{array}{l}\text { IAS } 28 \text { - Contabilidade para } \\
\text { investimentos em Associadas } \\
\text { (Investments in Associates) }\end{array}$} & $\begin{array}{l}\text { NBC T } 16.10 \text { - Avaliação e Mensuração } \\
\text { de Ativos e Passivos em Entidades do } \\
\text { Setor Público }\end{array}$ \\
\hline & & $\begin{array}{l}\text { NBC T } 16.2 \text { - Patrimônio e Sistemas } \\
\text { Contábeis }\end{array}$ \\
\hline $\begin{array}{l}\text { IPSAS } 8 \text { - Financial Reporting of } \\
\text { Interests in Joint Ventures }\end{array}$ & $\begin{array}{l}\text { IAS } 31 \text { - Tratamento contábil de } \\
\text { participação em empreendimentos em } \\
\text { conjunto (Interests in Joint Ventures) }\end{array}$ & $\begin{array}{l}\text { NBC T 16.10 - Avaliação e Mensuração } \\
\text { de Ativos e Passivos em Entidades } \\
\text { do Setor Público (Investimentos } \\
\text { Permanentes - participações em } \\
\text { empresas e em consórcios públicos ou } \\
\text { público-privados) }\end{array}$ \\
\hline \multirow[t]{2}{*}{$\begin{array}{l}\text { IPSAS } 9 \text { - Revenue from } \\
\text { Exchange Transactions }\end{array}$} & \multirow[t]{2}{*}{ IAS 18 - Receita (Revenue) } & $\begin{array}{l}\text { Resolução 1.111/07 CFC - PFCs - } \\
\text { Princípio de Competência (Accrual } \\
\text { Bassis) Portaria } 3 \text { STN/MPOG - } \\
\text { Receita sob enfoques Orçamentário e } \\
\text { Patrimonial. }\end{array}$ \\
\hline & & $\begin{array}{l}\text { NBC T 16.6 - Demonstrações } \\
\text { Contábeis - Demonstração do Resultado } \\
\text { Econômico (Custo de Oportunidade) }\end{array}$ \\
\hline $\begin{array}{l}\text { IPSAS } 10 \text { - Financial Reporting } \\
\text { in Hyperinflationary Economies }\end{array}$ & $\begin{array}{l}\text { IAS } 29 \text { - Demonstrações financeiras em } \\
\text { economias hiperinflacionárias (Financial } \\
\text { Reporting in Hyperinflationary } \\
\text { Economies) }\end{array}$ & $\begin{array}{l}\text { Resolução 1.111/07-PFCs - } \\
\text { Atualização Monetária }\end{array}$ \\
\hline $\begin{array}{l}\text { IPSAS } 11 \text { - Construction } \\
\text { Contracts }\end{array}$ & $\begin{array}{l}\text { IAS } 11 \text { - Contratos de construção } \\
\text { (Construction Contracts) } \\
\end{array}$ & N/A \\
\hline IPSAS 12 - Inventories & IAS 2 - Estoques (Inventories) & $\begin{array}{l}\text { NBC T } 16.10 \text { - Avaliação e Mensuração } \\
\text { de Ativos e Passivos em Entidades do } \\
\text { Setor Público }\end{array}$ \\
\hline IPSAS 13 -Leases & IAS 17 - Arrendamentos (Leases) & N/A \\
\hline $\begin{array}{l}\text { IPSAS } 14 \text { - Events after the } \\
\text { Reporting Date }\end{array}$ & $\begin{array}{l}\text { IAS } 10 \text { - Eventos subsequentes à data } \\
\text { do balanço patrimonial (Events after the } \\
\text { Balance Sheet Date) }\end{array}$ & N/A \\
\hline $\begin{array}{l}\text { IPSAS } 15 \text { - Financial } \\
\text { Instruments: Disclosure and } \\
\text { Presentation }\end{array}$ & $\begin{array}{l}\text { IAS } 32 \text { - Instrumentos Financeiros: } \\
\text { divulgação e apresentação (Financial } \\
\text { Instruments: Disclosure and } \\
\text { Presentation) } \\
\end{array}$ & N/A \\
\hline IPSAS 16 - Investment Property & $\begin{array}{l}\text { IAS } 40 \text { - Propriedades para investimento } \\
\text { (Investment Property) }\end{array}$ & N/A \\
\hline \multirow{3}{*}{$\begin{array}{l}\text { IPSAS } 17 \text { - Property, Plant and } \\
\text { Equipment }\end{array}$} & \multirow{3}{*}{$\begin{array}{l}\text { IAS } 16 \text { - Ativo Imobilizado (Property, } \\
\text { Plant and Equipment) }\end{array}$} & $\begin{array}{l}\text { NBC T } 16.2 \text { - Patrimônio e Sistemas } \\
\text { Contábeis }\end{array}$ \\
\hline & & NBC T 16.5 - Registro Contábil \\
\hline & & $\begin{array}{l}\text { NBC T 16.9 - Depreciação, Amortização } \\
\text { e Exaustão }\end{array}$ \\
\hline \multirow[t]{2}{*}{ IPSAS 18 - Segment Reporting } & \multirow{2}{*}{$\begin{array}{l}\text { IAS } 14 \text { - Relatórios por segmento } \\
\text { (Segment Reporting) }\end{array}$} & $\begin{array}{l}\text { NBC T } 16.1 \text { - Conceituação, Objeto e } \\
\text { Campo de Aplicação }\end{array}$ \\
\hline & & (Unidade Contábil) \\
\hline \multirow{2}{*}{$\begin{array}{l}\text { IPSAS } 19 \text { - Provisions, } \\
\text { Contingent Liabilities, Contingent } \\
\text { Assets }\end{array}$} & \multirow{2}{*}{$\begin{array}{l}\text { IAS } 37 \text { - Provisões, passivos e ativos } \\
\text { contingentes (Provisions, Contingent } \\
\text { Liabilities and Contingent Assets) }\end{array}$} & NBC T 16.8 - Controle Interno \\
\hline & & $\begin{array}{l}\text { NBC T } 16.10 \text { - Avaliação e Mensuração } \\
\text { de Ativos e Passivos em Entidades do } \\
\text { Setor Público }\end{array}$ \\
\hline
\end{tabular}




\begin{tabular}{|c|c|c|}
\hline IPSAS/IFAC & IAS-IFRS/IASB & NBCTSPs/CFC \\
\hline $\begin{array}{l}\text { IPSAS } 20 \text { - Related Party } \\
\text { Disclosures }\end{array}$ & $\begin{array}{l}\text { IAS } 24 \text { - Divulgações das partes } \\
\text { relacionadas (Related Party Disclosures) }\end{array}$ & N/A \\
\hline $\begin{array}{l}\text { IPSAS } 21 \text { - Impairment of Non- } \\
\text { cash-generating Assets }\end{array}$ & $\begin{array}{l}\text { IAS } 36 \text { - Redução no valor recuperável } \\
\text { de ativos (Impairment of Assets) }\end{array}$ & $\begin{array}{l}\text { NBC T } 16.10 \text { - Avaliação e Mensuração } \\
\text { de Ativos e Passivos em Entidades do } \\
\text { Setor Público }\end{array}$ \\
\hline $\begin{array}{l}\text { IPSAS } 22 \text { - Disclosure of } \\
\text { Financial Information About the } \\
\text { General Government Sector }\end{array}$ & N/A & N/A \\
\hline \multirow{2}{*}{$\begin{array}{l}\text { IPSAS } 23 \text { - Revenue from Non- } \\
\text { Exchange Transactions (Taxes } \\
\text { and Transfers) }\end{array}$} & & $\begin{array}{l}\text { Resolução 1.111/07 - PFCs - Princípio } \\
\text { de Competência. }\end{array}$ \\
\hline & & $\begin{array}{l}\text { Demonstração do Resultado Econômico } \\
\text { (Custo de Oportunidade) }\end{array}$ \\
\hline $\begin{array}{l}\text { IPSAS } 24 \text { - Presentation of } \\
\text { Budget Information in Financial } \\
\text { Statements }\end{array}$ & & $\begin{array}{l}\text { NBC T } 16.3 \text { - Planejamento e seus } \\
\text { Instrumentos sob o Enfoque Contábil }\end{array}$ \\
\hline IPSAS 25 - Employee Benefits & & $\mathrm{N} / \mathrm{A}$ \\
\hline $\begin{array}{l}\text { IPSAS } 26 \text { - Impairment of Cash- } \\
\text { Generating Assets }\end{array}$ & & $\begin{array}{l}\text { NBC T } 16.10 \text { - Avaliação e Mensuração } \\
\text { de Ativos e Passivos em Entidades do } \\
\text { Setor Público }\end{array}$ \\
\hline
\end{tabular}

\section{Quadro 1: Convergência IPSAS x IAS/IFRS x NBCASPs}

Fonte: Elaborado pelos autores

O nível de convergência apresentado pelas NBCTSPs, com base na relação apresentada no Quadro 1 e na análise de cada tópico conceitual, apresenta-se no Quadro 2:

\begin{tabular}{|l|c|c|c|c|}
\hline NBCTSPs & $\begin{array}{c}\text { Tópicos } \\
\text { conceituais }\end{array}$ & $\begin{array}{c}\text { Total de tópicos válidos } \\
\text { (a) }\end{array}$ & $\begin{array}{c}\text { Tópicos contemplados pelas } \\
\text { IPSAS correspondentes } \\
\text { (b) }\end{array}$ & $\begin{array}{c}\text { Percentual de convergência } \\
\text { (b/a) } \mathbf{x ~ 1 0 0}\end{array}$ \\
\hline NBCT 16.1 & 2 a 10 & 9 & 4,29 & $47,67 \%$ \\
\hline NBCT 16.2 & 2 a 13 & 12 & 6,5 & $54,17 \%$ \\
\hline NBCT 16.3 & 2 a 6 & 5 & 3,67 & $73,40 \%$ \\
\hline NBCT 16.4 & 2 a 11 & 10 & 1 & $10,00 \%$ \\
\hline NBCT 16.5 & 2 a 25 & 24 & 0 & $0,00 \%$ \\
\hline NBCT 16.6 & 2 a 41 & 40 & 27,7 & $69,25 \%$ \\
\hline NBCT 16.7 & 2 a 8 & 7 & 5 & $71,43 \%$ \\
\hline NBCT 16.8 & 2 a 12 & 11 & 1 & $9,09 \%$ \\
\hline NBCT 16.9 & 2 a 16 & 15 & 7,63 & $50,87 \%$ \\
\hline NBCT 16.10 & 2,4 a 40 & 38 & 15,5 & $40,79 \%$ \\
\hline
\end{tabular}

\section{Quadro 2: Percentual de convergência conceitual NBCTSPs/IPSAS}

Fonte: Elaborada pelos autores

A NBC T 16.1, comparada conceitualmente com as IPSAS 1 e 18, apresenta os conceitos, objeto e campo de aplicação das Normas Brasileiras de Contabilidade Aplicadas ao Setor Público. Esta norma é convergente nos seguintes aspectos: 
- Características das informações, especialmente em relação à compreensibilidade, utilidade, bem como no conceito de controle de recursos vinculados ao controle social (IPAS 1 e 18).

- $\quad$ No conceito das normas e técnicas aplicadas ao segmento (IPSAS 1).

- $\quad$ Na definição do campo de aplicação, das entidades abrangidas e do nível de aplicação das normas - aplicação integral ou parcial (IPSAS 1 e 18).

- $\quad$ No conceito de unidade contábil e seu reflexo na apuração de informações, controle e consolidação (IPSAS 1 e 18).

A análise das IPSAS 1 e 18 revela que os conceitos de Patrimônio Público, Setor Público, Contabilidade Pública, Recurso Público e de Ações de Promoção Social não são encontrados ou detalhados da maneira didática como na NBCT 16.1. Esses conceitos representam em média 52\% dos tópicos apresentados na norma.

A NBC T 16.2, comparada conceitualmente com a IPSAS 7, dispõe sobre o Patrimônio e Sistemas Contábeis. Esta norma é convergente nos seguintes aspectos:

- $\quad$ No que se refere ao conceito de circulante, não circulante, conversibilidade, exigibilidade e unidade contábil, sendo este último um conceito repetitivo, pois a NBC T 16.1 também apresenta esta definição.

- Quanto à classificação do patrimônio público: Ativo, Passivo e Patrimônio Líquido, bem como os conceitos associados a cada um.

- Quanto às características do ativo circulante: de realização imediata, até o termino do exercício seguinte. Também em relação aos outros ativos, a classificar no grupo não circulante, quando suas características não se enquadrem nas anteriores.

- Quanto à classificação do passivo em circulante e não circulante, de acordo com o prazo de exigibilidade.

A referida norma internacional não define e/ou contempla os conceitos vinculados aos tópicos restantes: Patrimônio Público (conceito repetitivo, também citado na NBCT 16.1). Não há referencia sobre classificação de passivos quando a entidade faz o papel de "fiel depositária" de valores e/ou retenções de terceiros; não há referência ao conceito de sistema contábil; e não há clareza na definição conceitual e de integração de subsistemas, como o orçamentário, financeiro, patrimonial, de custos e de compensação, que são bem definidos pela NBCT 16.2

A NBC T 16.3, comparada conceitualmente com a IPSAS 24, apresenta conceitos associados ao planejamento e seus instrumentos sob o enfoque contábil. Esta norma é convergente nos seguintes aspectos:

- $\quad$ Avaliação de desempenho e planejamento das entidades do setor público.

- $\quad \mathrm{Na}$ avaliação do comparativo de metas programadas e metas realizadas, com as diferenças sinalizadas em notas explicativas ou demonstrativos complementares.

- Na evidenciação, em termos quantitativos e qualitativos, de informações para a tomada de decisões (conteúdo, execução, implementação, avaliação).

- Informações a serem detalhadas por metas, ações, valores, ano.

A norma brasileira ressalta a importância da adoção de "planos hierarquicamente interligados", os quais consistem na definição de etapas do planejamento (programas e ações) nos níveis estratégico e operacional, além da avaliação das restrições no desenvolvimento dessas etapas, bem como dos resultados (impacto) obtidos. Essa lógica na definição do planejamento não é ressaltada pela norma internacional.

A NBC T 16.4, comparada conceitualmente com a IPSAS 9, apresenta os conceitos, sobre transações no setor público. Esta norma é convergente nos seguintes aspectos:

- No conceito de transações no setor público, na avaliação de eventos que promovam alterações qualitativas e quantitativas no patrimônio, orientada segundo os princípios e normas de contabilidade. 


\section{repec}

A norma internacional não menciona a classificação das transações do setor público em econômico-financeira e administrativa. O conceito de variações patrimoniais e transações que envolvem valores de terceiros também não são contemplados da maneira sistemática que a NBCASP apresenta.

A NBC T 16.5, comparada conceitualmente com a IPSAS 17, apresenta os conceitos associados ao registro contábil. O conteúdo dessa norma, da forma como é exposto, das classificações e natureza apresentados não convergem com a referida norma internacional.

A NBC T 16.6, comparada conceitualmente com as IPSAS 1, 2, 18, 19, apresenta o conteúdo sobre Demonstrações Contábeis. Embora a norma seja repetitiva em conceitos sobre circulante, não circulante, conversibilidade, exigibilidade e unidade contábil (conceitos também apresentados na NBCT 16.2). Esta norma é convergente nos seguintes aspectos:

- Conceito de circulante e não circulante; demonstração contábil como técnica; designações genéricas; versões simplificadas de demonstrativos; característica da conversibilidade de ativos; característica da exigibilidade de obrigações; esclarecimentos sobre métodos direto e indireto referentes a fluxos de caixa.

- $\quad$ Na definição de demonstrações contábeis: Balanço Patrimonial, Demonstração do Fluxo de Caixa.

- Sobre a evidenciação em demonstrativos anexos e notas explicativas.

- $\quad$ Sobre informações para registro extraídas de documentos comprobatórios.

- Sobre a identificação da entidade, da autoridade responsável e do contabilista que elaborou e emitiu as demonstrações.

- Sobre a apresentação dos valores do período anterior, para efeitos de comparabilidade.

- Sobre agrupamento de algumas informações, de pequeno saldo, mas semelhantes, em contas de designação genérica (materialidade).

- Da publicação dos saldos em unidades de milhar ou milhão para efeitos de publicação.

- Sobre as contas retificadoras, redutoras do grupo de origem.

- Quanto ao Balanço Patrimonial: conceito de ativo, passivo, patrimônio líquido e contas de compensação.

- Quanto ao Patrimônio Líquido ter seu resultado segregado dos resultados acumulados dos períodos anteriores.

- Quanto à apresentação da classificação circulante e não circulante.

- Quanto ao conceito de circulante e não circulante.

- Quanto à ordem de exigibilidade e conversibilidade.

- Quanto à demonstração dos fluxos de caixa (conceito, método direto e indireto, classificação em caixa gerado pelas atividades operacionais, de investimento e de financiamento.

- Quanto às notas explicativas: conceito aplicações.

A referida norma brasileira não converge com as normas internacionais citadas anteriormente nos seguintes aspectos:

- Não há definição clara do balanço orçamentário, balanço financeiro, das demonstrações de variação patrimonial e demonstração de resultado econômico, embora seja possível encontrar orientações de procedimentos que sejam pré-requisitos para a sua elaboração, existe o conceito de receita, despesa e a sua classificação em relação à natureza e função, à sua estimativa e realização. Não há referência a variações quantitativas e qualitativas, bem como aos conceitos de receita econômica e custo de oportunidade.

- Não foram encontradas indicações sobre local de publicação ou divulgação dos demonstrativos contábeis (imprensa oficial, meios eletrônicos, meios de acesso e comunicação das datas de disponibilização dessas informações ao público/sociedade, remessa a órgãos de controle interno e externo), embora a ênfase seja na divulgação das informações e na transparência, não há indicação direta de qual meio utilizar. 
A NBC T 16.7, comparada conceitualmente com as IPSAS 6, 7 e 27, apresenta os conceitos e orientações sobre Consolidação das Demonstrações Contábeis. Esta norma é convergente nos seguintes aspectos:

- Quanto ao conceito de consolidação das demonstrações contábeis e quanto à relação de dependência entre as entidades do setor público: Orçamentária e Regimental. Também quanto ao conceito de unidade contábil consolidada.

- $\quad$ A norma converge no que se refere aos procedimentos de consolidação: avaliação da relação de dependência, da totalidade das transações que envolvem as entidades, bem como da exclusão dos efeitos de transações entre elas.

- Sobre as demonstrações serem levantadas na mesma data, com defasagem aceitável de até 3 meses, cujos efeitos deverão ser divulgados em notas explicativas.

- Sobre informações complementares que deverão constar em notas explicativas: identificação e características das entidades participantes do processo, procedimentos efetuados, razões da adoção de critérios não uniformes, natureza e montante de ajustes, eventos subsequentes ao encerramento.

As normas internacionais não enfatizam a adoção de documentos auxiliares para registro dos procedimentos de consolidação das entidades.

A NBC T 16.8, comparada conceitualmente com a IPSAS 19, apresenta conceitos associados ao controle interno. Esta norma é convergente nos seguintes aspectos:

- No conceito dos riscos e fatos imprevisíveis que poderão afetar a qualidade da informação contábil.

Não há referência na norma internacional do conceito de controle interno, de sua aplicação nos diversos níveis da entidade, da classificação entre operacional, contábil, normativo, bem como sobre mapeamento de risco, avaliação do risco e procedimentos de prevenção, detecção, monitoramento com auxílio de um sistema de informações.

A NBC T 16.9, comparada conceitualmente com as IPSAS 17 e 26, apresenta os conceitos de Depreciação, Amortização e Exaustão. Esta norma é convergente nos seguintes aspectos:

- $\quad$ Conceito de depreciação e amortização; definição do valor depreciável, valor residual e vida útil econômica.

- $\quad$ Na orientação de revisão do valor residual e da vida útil do ativo, periodicamente.

- No reconhecimento da depreciação, amortização até o momento em que o valor líquido do bem seja igual ao seu valor residual, bem como o início desse reconhecimento deve iniciar quando o bem estiver em condições de uso.

- Definição dos fatores para estimativa da vida útil de um ativo: benefícios futuros, desgaste físico, obsolescência tecnológica, limites legais ou contratuais sobre o uso.

- $\quad$ Os métodos de apuração deverão ser compatíveis com a vida útil e aplicados uniformemente.

- Quanto à orientação do cálculo da depreciação para bens imóveis, que deverão tomar por base o custo de construção, deduzido o valor dos terrenos.

- Quanto à divulgação em notas explicativas: método utilizado, vida útil, valor contábil bruto acompanhado dos valores de depreciação, amortização, acumulados no início e fim do período; e mudanças efetuadas em qualquer informação anterior.

As divergências estão associadas à ausência, no conteúdo das normas internacionais comparadas, do conceito associado ao termo exaustão, definição do valor contábil bruto e valor contábil líquido. Os aspectos associados ao registro da depreciação, amortização e exaustão, a indicação do reconhecimento em contas de resultado também não são mencionados nas IPSAS comparadas. Outros aspectos não contemplados pelas IPSAS são: 


\section{repec}

- $\quad$ o fato de que ativos que se tornam obsoletos ou temporariamente inativos continuam depreciando ou amortizando, conforme o caso;

- $\quad$ sobre definição da vida útil por laudo técnico;

- $\quad$ no caso de bens, quando reavaliados, o cálculo da depreciação, amortização ou exaustão deverá ter como base o novo valor;

- $\quad$ indicação de alguns ativos específicos, que não são depreciáveis como animais destinados à exposição e à preservação;

- $\quad$ em relação aos métodos de apuração da depreciação: soma de dígitos e o de unidades produzidas;

A NBC T 16.10, comparada conceitualmente com as IPSAS 7, 8, 12, 17, 19, 21, 26, apresenta os conceitos da avaliação e mensuração de ativos e passivos em entidades do setor público. Esta norma é convergente nos seguintes aspectos:

- Definição de influencia significativa.

- Conceito de reavaliação.

- Conceito de redução ao valor recuperável.

- Conceito de Valor de mercado (fair value).

- Conceito de valor realizável líquido.

- Conceito de valor recuperável.

- $\quad$ Orientações sobre reconhecimento dos riscos associados ao não recebimento de dívidas.

- Orientações sobre avaliação dos direitos e obrigações prefixados, ajustados a valor presente.

- Sobre as provisões que deverão ser estimadas com base nos valores prováveis de realização para ativos e de reconhecimento para passivos.

- Sobre avaliação de estoques, registrados pelo valor de aquisição, produção ou de construção.

- Sobre classificação dos gastos de distribuição, administração e financeiros, considerados como despesas do período em que ocorrem.

- $\quad$ Orientações sobre quando o valor de aquisição, de produção ou construção for inferior ao valor de mercado, este último deverá ser adotado.

- Q Quanto às diferenças observadas no estoque (ajustes na avaliação), deverão refletir em contas de resultado.

- Quanto à adoção do método de equivalência patrimonial quando há influência significativa na administração de uma empresa, ao contrário adotar o método de custo. Todos os ajustes dessas transações deverão constar em contas de resultado.

- Quanto ao ativo imobilizado que deverá ser avaliado pelo valor de aquisição, de produção ou construção, incluindo gastos adicionais.

- Se o ativo imobilizado tiver período de vida útil econômica limitada, o cálculo da depreciação e amortização deverá refletir essa condição.

- Os gastos posteriores à aquisição ou registro do ativo deverá ser incorporado ao seu valor apenas quando o fato proporcionar geração de benefícios futuros, caso contrário deverá ser classificado como despesa do período que ocorreu.

- Sobre reavaliação e redução ao valor recuperável (impairment) apenas no que se refere à adoção do valor justo ou valor de mercado, na data de encerramento do balanço. Os ajustes decorrentes dessas reavaliações deverão constar em contas de resultado.

O conteúdo da referida norma brasileira que não é contemplado ou não converge com as normas internacionais correspondentes é:

- $\quad$ conceitos de avaliação patrimonial, mensuração, valor de reavaliação, valor de aquisição, valor contábil bruto, valor líquido contábil; 
- $\quad$ avaliação das disponibilidades pelo valor original. Quando avaliados em moeda estrangeira, deverá ser convertida a taxa de câmbio vigente na data de balanço;

- $\quad$ aplicações financeiras de liquidez imediata contabilizadas pelo valor original, atualizadas até a data balanço, e reflexos da atualização registrados em resultado;

- $\quad$ avaliação dos direitos e obrigações pelo valor original. Quando avaliados em moeda estrangeira, deverá ser convertida a taxa de câmbio vigente na data de balanço; quando pós-fixados, deverão ser ajustados com os encargos devidos até a data do balanço, com os reflexos no resultado devidamente contabilizados;

- $\quad$ a norma brasileira define o custo médio ponderado para mensuração e avaliação de saídas para estoque. A IPSAS 12 estabelece condições para adoção dos três métodos a seguir: Preço Específico, Custo Médio e FIFO (first in first out).

- $\quad$ a referida norma brasileira orienta a avaliação do estoque pelo valor de mercado no caso de deterioração física parcial, obsolescência ou fatores análogos, enquanto a IPSAS 12 orienta a avaliação pelo valor realizável líquido;

- a norma brasileira define o critério de avaliação pelo valor realizável líquido para refugos e resíduos (estoque), enquanto a IPSAS 12 orienta o registro em despesas do período, sem constar no custo de produção;

- $\quad$ definição do valor de mercado para estoques de animais e produtos agrícolas quando a atividade for considerada primária e cujos custos de produção sejam de difícil mensuração. A IPSAS 12 faz referência à avaliação pelo valor líquido de realização quando a venda está assegurada;

- $\quad$ definição do valor de aquisição ou produção para ativos intangíveis "direitos que tenham por objeto bens incorpóreos”. A IPSAS 26 faz referência à avaliação pelo valor justo;

- conceitos não contemplados nas IPSAS avaliadas:

- Sobre avaliação de ativos imobilizados: obtidos por doação, sobre transferência desses ativos, sobre bens de uso comum que absorvem ou absorveram recursos públicos.

- Sobre ativos intangíveis: critérios de avaliação quando obtidos a título gratuito, avaliação dos gastos ou resultados obtidos após a aquisição ou registro deles.

- Sobre o diferido: critério de avaliação das despesas pré-operacionais ou gastos de reestruturação.

- Sobre reavaliação e valor recuperável: definições sobre a impossibilidade de mensuração pelo valor de mercado, estimação do valor justo (para bens imóveis específicos) a partir do valor de reposição, estabelecimento do valor de reposição do ativo com base no preço de compra ou construção de bem semelhante ou similar.

\section{CONCLUSÃO}

A análise do estágio de convergência conceitual entre as normas brasileiras de contabilidade aplicadas ao setor público (NBCTSPs) e as IPSAS demonstrou que, por ordem de convergência avaliada, os tópicos referentes à NBC T 16.3 - planejamento e seus instrumentos sob o enfoque contábil - e NBC T 16.7 - consolidação das demonstrações contábeis - foram as normas que mais convergiram com as IPSAS, apresentando um percentual de aderência de 73,40\% e 71,43\%, respectivamente. As normas que apresentaram um percentual de aderência abaixo de 10\% de sua base conceitual foram: NBC T $16.4-$ transações no setor público, NBC T 16.5 - registro contábil e NBC T 16.8 - controle interno. Pode-se inferir que as normas que mais convergiram mantenham em seu arcabouço conceitos mais atrelados à atualidade global, no que tange ao planejamento e ao processo de consolidação de demonstrações. No que se refere a transações no setor público, registro contábil e controle interno, predominam as características próprias (cultura, regulação, economia), o que poderá justificar o pequeno percentual de convergência. Identificou-se, no comparativo, que as IPSAS apresentam-se mais voltadas à orientação do "como 


\section{repec}

fazer", enquanto nas normas brasileiras predomina a exposição conceitual, argumentativa. Há divergências constantes na avaliação de ativos, principalmente na adoção do valor justo, valor de mercado ou valor realizável líquido, oriundos de práticas contábeis diferenciadas. Em contrapartida, a prática brasileira é muito mais coerente na classificação de sistemas orçamentário, financeiro, patrimonial e na definição de demonstrativos específicos para cada sistema, proporcionando o desempenho efetivo da accountability.

\section{REFERÊNCIAS}

ANTHONY, Robert T. Rethinking the Rules of Financial Accounting - Examining the Rules for Proper Reporting. McGraw-Hill (USA), 2003.

CFC - Conselho Federal de Contabilidade - Princípios fundamentais e normas brasileiras de contabilidade/ Conselho Federal de Contabilidade. 3. ed. Brasília: CFC, 2008.

IASB - International Accounting Standard Board. Discussion Paper - Fair Value Measurements (part 1), November 2006.

MANZANO, Mercedes Palacios; CONESA, Isabel Martínez. El proceso de armonización contable en latinoamérica: camino hacia las normas internacionales. Revista Contabilidade e Finanças, São Paulo, n. 39, p. 103-117, Set./Dez. 2005

POHLMANN, Marcelo Coletto. Harmonização contábil no MERCOSUL: a profisssão e o processo de emissão de normas - uma contribuição. Caderno de Estudos FIPECAFI, nº ${ }^{12}$, São Paulo, FIPECAFI, p.1-19, set/1995.

POPPER, (Sir) Karl Raimund. A lógica da pesquisa científica. 2. Edição. São Paulo. Cultrix, 1975

POPPER, (Sir) Karl Raimund. Conjecturas e Refutações. Brasília: Editora UNB, 1982.

SZUSTER, Natan; SZUSTER, Fortunnée Rechtman; SZUSTER, Flávia Rechtman. Contabilidade: atuais desafios e alternativa Para seu melhor desempenho. Revista Contabilidade e Finanças. São Paulo, n. 38, p. 20 - 30, Maio/Ago. 2005

ZEFF, Stephen A. Some obstacles to global financial reporting comparability and convergence at a high level of quality. The British Accounting Review, n. 39, 2007 